\title{
Spontaneous cerebro-spinal fluid leaks
}

\section{Fuite spontanée de liquide céphalo-rachidien}

\author{
C. Petit $\cdot$ N. Thoma $\cdot$ N. Modruz $\cdot$ Y. Auffret
}

Reçu le 16 juillet 2013; accepté le 9 octobre 2013

(C) SFMU et Springer-Verlag France 2013

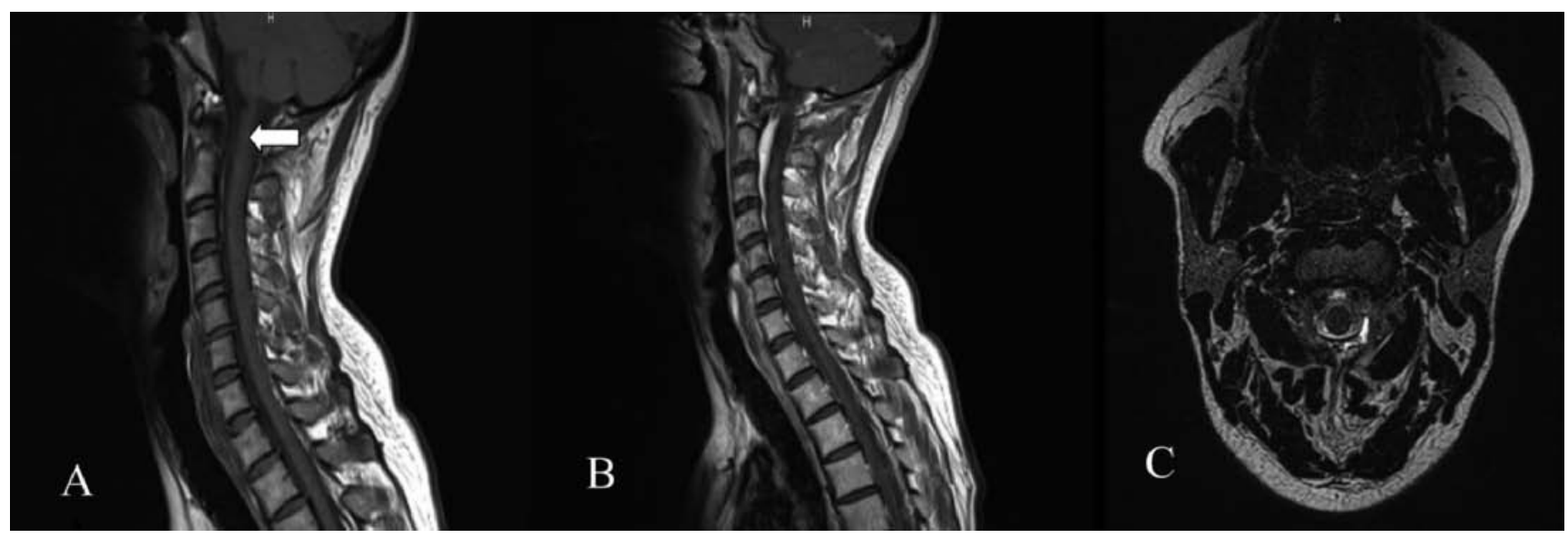

Fig. 1 IRM médullaire. Séquence T1 sans gadolinium, coupe sagittale (A) : absence de signal (flèche blanche large). Séquence T1 avec gadolinium, coupe sagittale $(\mathrm{B})$ : hyperémie du plexus veineux de la première à la quatrième vertèbre cervicale en épidural antérieur (flèches blanches pleines). Séquence 3DCIS, coupe axiale (C) : collection liquidienne périmédullaire (flèches pointillées)

Une femme de 44 ans sans antécédent consulte aux urgences pour des céphalées résistantes aux traitements médicamenteux. L'anamnèse retrouve un caractère postural des céphalées et l'absence de traumatisme. À l'examen clinique, il existe une céphalée à la station debout qui disparaît lorsque la patiente est en position allongée. Une cervicalgie gauche est associée à la céphalée. Pas d'autres signes fonctionnels associés. L'imagerie par résonance magnétique (IRM) retrouve un aspect compatible avec une fuite de liquide céphalorachidien (LCR) (Fig. 1). Le diagnostic retenu est celui d'une hypotension spontanée du
LCR [1]. Après échec d'un traitement symptomatique, la patiente a bénéficié d'un traitement par blood-patch. Ce n'est qu'après le troisième blood-patch que la clinique se normalise durablement. Aucune imagerie de contrôle n'a été réalisée en l'absence de récidive symptomatique.

\section{Référence}

1. Mokri B (2013) Spontaneous low pressure, low CSF volume headaches: spontaneous CSF leaks. Headache 53:1034-53

C. Petit $(\bowtie) \cdot$ N. Thoma $\cdot$ Y. Auffret

Service urgences-Smur, centre hospitalier de Cornouaille,

14, avenue Y. Thépot, F-29000 Quimper, France

e-mail : petit-caroline@hotmail.fr

\section{N. Modruz}

Service de radiologie, centre hospitalier de Cornouaille,

14, avenue Y. Thépot, F-29000 Quimper, France 